\title{
Prognostic significance of lymphocyte patterns in multiple myeloma patients after autologous transplant
}

Martin STORK ${ }^{1}$, Renata BEZDEKOVA ${ }^{2}$, Romana KRALOVA ${ }^{2}$, Viera SANDECKA ${ }^{1, *}$, Zdenek ADAM ${ }^{1}$, Marta KREJCI ${ }^{1}$, Ivanna BOICHUK ${ }^{1}$, Zdenka KNECHTOVA ${ }^{1}$, Lucie BROZOVA ${ }^{3}$, Sabina SEVCIKOVA ${ }^{4}$, Lucie RIHOVA², Ludek POUR ${ }^{1}$

${ }^{1}$ Department of Internal Medicine, Hematology and Oncology, University Hospital Brno, Brno, Czech Republic; ${ }^{2}$ Department of Clinical Hematology, University Hospital Brno, Brno, Czech Republic; ${ }^{3}$ Institute of Biostatistics and Analyses, Ltd., Brno, Czech Republic; ${ }^{4}$ Babak Myeloma Group, Department of Pathophysiology, Faculty of Medicine, Masaryk University, Brno, Czech Republic

${ }^{*}$ Correspondence: sandecka.viera@fnbrno.cz

Received August 14, 2020 / Accepted December 30, 2020

\begin{abstract}
Despite the high efficacy of current induction regimens, most multiple myeloma (MM) patients relapse over time. The link between changes in the immune system and the prognosis of the disease is still not entirely clear. Therefore, we analyzed whether the pattern of bone marrow (BM) lymphocytes during routine BM examination after autologous stem cell transplant (ASCT) is related to disease prognosis or MRD negative complete remission. From 2009 to 2018, 98 MM patients underwent routine BM testing after the first ASCT. Using multi-parametric flow cytometry, twelve BM lymphocyte subtypes were analyzed. In $60 \%$ of patients who achieved a complete response (CR), MRD by flow cytometric analysis (sensitivity threshold 10-6) was evaluated. We found an association of relative proportion of BM lymphocyte subtypes with treatment response, progression-free survival (PFS), overall survival (OS), and minimal residual disease (MRD) negativity. Higher relative proportion of memory B cells was associated with inferior median PFS [HR 1.089 (95\% CI: 1.023-1.160), p=0.008] and median OS [HR 1.170 (95\% CI: 1.074-1.274), $\mathrm{p}<0.001$ ]. In non-responding patients (minimal response and worse), higher proportion of memory B cells was found when compared to patients achieving CR [3.8\% (range 0.5-35.0) vs. 1.0\% (range 0.1-12.5); $\mathrm{p}=0.001$ ]. No significant association of BM lymphocyte subtypes proportion with MRD negative CR was found. Our results show that changes in BM lymphocyte subsets including memory B cells may have prognostic value in MM patients after ASCT.
\end{abstract}

Key words: multiple myeloma, minimal residual disease, lymphocyte, flow cytometry

The introduction of new anti-myeloma drugs, such as proteasome inhibitors (PI) and immunomodulatory drugs (IMIDs), combined with high dose chemotherapy followed by autologous stem cell transplant (ASCT) led to a significant improvement of prognosis of younger multiple myeloma (MM) patients $[1,2]$. Modern induction regimens followed by ASCT are capable of inducing treatment response in almost all MM patients, and a large number of patients can achieve complete response (CR) $[3,4]$. The depth of treatment response strongly correlates with the length of progression-free survival (PFS) and overall survival (OS) [5].

Thus, the best possible prognosis can be expected in MM patients achieving complete response (CR) without the minimal residual disease (MRD) in bone marrow (BM) detected by new generation sequencing (NGS) or multiparametric flow cytometry (MFC) [6-8]. However, even these MRD-negative patients often relapse [9]. On the other hand, there is a group of patients who achieve long-term remission
( $>10$ years) independently of their MRD negative status or even achievement of CR $[10,11]$. It is likely that immune surveillance of the disease plays a key role in these patients [12].

Preclinical studies have confirmed that specific lymphocyte subpopulations are actively and directly involved in the myeloma-specific immune response. These include NK cells [13], cytotoxic CD8 ${ }^{+} \mathrm{T}$ cells [14], and possibly NKT lymphocytes [15]. Moreover, in a few clinical trials, higher levels of some lymphocyte subpopulations were associated with a more favorable prognosis. Higher levels of $\mathrm{CD}^{+}{ }^{+} \mathrm{T}$-cells and $\mathrm{CD} 19^{+} \mathrm{B}$-cells after induction treatment in peripheral blood (PB) are associated with longer PFS and/or OS [16]. A higher proportion of $\mathrm{CD} 19^{+} \mathrm{B}$-cells in patients before ASCT and $\gamma \delta \mathrm{T}$ cells or NK cells in patients after ASCT resulted in longer PFS or OS $[17,18]$. In another paper, MM patients with sustained long-term remission showed a higher proportion of cytotoxic $\mathrm{CD}^{+} \mathrm{T}$ cells and a lower proportion of 
Treg lymphocytes [11]. In another analysis of patients after lenalidomide treatment, a higher proportion of naive and memory B-cells in BM was associated with a longer time to progression (TTP) and OS. In contrast, excess of B-cell precursors was associated with a worse prognosis [19].

In $\mathrm{MM}$ patients, a different distribution of lymphocyte subpopulations can be found in the PB and BM niches [20, 21]. Previous analyses were based predominantly on $P B$ lymphocyte subpopulations.

Based on these facts, we assumed that specific BM lymphocyte pattern after the first ASCT may have a prognostic significance in PFS or OS duration. Moreover, in patients achieving MRD negativity, a specific BM lymphocyte pattern may be present.

\section{Patients and methods}

Characteristics of the patient population. We retrospectively analyzed 98 newly diagnosed MM patients, who were treated with induction treatment followed by ASCT. All patients were treated at the Department of Internal Medicine, Hematology and Oncology, University Hospital Brno, Czech Republic between September 2009 and October 2018. Patients were followed up and their data were analyzed in March 2019.

We enrolled all patients, who underwent induction treatment based on modern anti-myeloma drugs (PI and/ or IMIDs) and who agreed with routine BM assessment including MFC after ASCT. Enrollment of patients was unbiased according to induction protocol. We excluded all patients who had BM assessment during any subsequent anti-myeloma treatment and patients with clinical or laboratory signs of infection, persisting cytopenia (i.e., treatmentrelated MDS, bone marrow failure, etc.), systemic autoimmune disease, or other malignancies.

All patients were treated according to the investigator's decision with the best available treatment. Patients were mobilized by cyclophosphamide $2.5 \mathrm{~g} / \mathrm{m}^{2}$ followed by G-CSF $10 \mathrm{IU} / \mathrm{kg}$. The patient underwent apheresis until a target CD $34^{+}$cell dose of $10 \times 10^{6} / \mathrm{kg}$ or more was achieved. All cells were divided into at least four grafts and subsequently cryopreserved for further use. The patient received a full (200 $\mathrm{mg} / \mathrm{m}^{2}$ ) dose of melphalan (MEL) as pre-transplant conditioning.

All acquired data were recorded in the RMG (Registry of Monoclonal Gammopathies) of the Czech Myeloma Group. All participants provided written informed consent with the inclusion of their data in the RMG. These consent forms were approved by the institutional Ethics board in accordance with the latest Helsinki declaration.

Bone marrow collection and immune profiling panels. $\mathrm{BM}$ samples were collected at the time of routine response assessment after ASCT. In all 98 patients, BM was collected at least 2 months (range 2-7) after ASCT. A wide range of BM sampling schedules was affected by the patient's decision or delay in case of non-serious infections.

BM samples of MM patients were analyzed by multiparametric flow cytometry. The following monoclonal antibodies (MoAbs) were used for surface analysis: CD45-PB (PB-684-T100; Exbio), CD45-PO (PO-684T100; Exbio), CD5-FITC (1F-482-T100; Exbio), CD19-PC7 (IM3628; Beckman Coulter), CD10-APC (1A-209-T100; Exbio), CD20-PerCP (PC-638-T100; Exbio), CD27-APCAlexaFluor750 (B12701; Beckman Coulter), CD34-PE (1P-664-T100; Exbio), CD56-APC (1A-789-T100; Exbio), CD38-APC-AlexaFluor750 (B49200; Beckman Coulter), CD38-PB (PB-366-T100; Exbio), CD138BV510 (2382590; Sony), CD138-PerCP (PC-814-T100; Exbio). Fixed and permeabilized cells (IntraPrep, A07803; Beckman Coulter) were used for intracellular staining of immunoglobulin light chains (kappa-FITC; C15623 and lambda-PE; C15189, both Beckman Coulter) regarding clonality assessment. The 8 -color flow cytometry was performed on BD FACSCanto ${ }^{\text {тm }}$ II with acquisition software Diva (BD Biosciences), and data were analyzed by Infinicyt software (Cytognos, Salamanca).

Analyzed CD $45^{+}$lymphocyte subpopulations were $\mathrm{CD} 19^{+}$ $\mathrm{B}$ cells incl. $\mathrm{CD} 34^{+} \mathrm{CD} 10^{-/+} \mathrm{CD} 20^{-}$preB I, CD $34^{-} \mathrm{CD} 10^{+} \mathrm{CD} 20^{-}$ preB II, $\mathrm{CD} 10^{+} \mathrm{CD} 20^{+}$immature $\mathrm{B}$ and $\mathrm{CD} 10^{-} \mathrm{CD} 20^{+}$mature B cells. T cells were $\mathrm{CD}^{1} 9^{-} \mathrm{CD}^{+}$and $\mathrm{NK}$ cells were calculated as rest of $\mathrm{CD}^{-} \mathrm{CD} 19^{-}$lymphocytes. NK subset of $\mathrm{CD}^{-} 6^{+}$ NK/NKT lymphocytes was defined as $\mathrm{CD}^{+} 8^{+}$. Memory subpopulations were $\mathrm{CD} 19^{+} \mathrm{CD} 27^{+} \mathrm{B}$ and $\mathrm{CD} 19^{-} \mathrm{CD} 27^{+} \mathrm{T}$ lymphocytes, where activated memory $\mathrm{T}$ cells were defined as $\mathrm{CD} 38^{+}$. Clonality assessment was done on $\mathrm{CD} 38^{+} \mathrm{CD} 138^{+}$ PCs, and clonal PCs were detected according to phenotype from the time of diagnosis based on the expression of CD45, CD19, CD56, and CD27 together with cytoplasmic kappa/ lambda verification.

The number of analyzed cells was $10 \times 10^{6}$ if possible or the entire volume of $\mathrm{BM}$ sample, minimum $1 \times 10^{6}$. The limit of detection (LOD) for MRD positivity was 20 clonal PCs from analyzed leukocytes, the sample was classified as MRD positive above that LOD.

Endpoints and response assessment. Treatment response and survival intervals (PFS, OS) were analyzed. Survival intervals were assessed from the beginning of induction treatment. The response was assessed according to the current International Myeloma Working Group (IMWG) criteria [22].

The primary endpoint of this analysis was the correlation between BM relative lymphocyte subtype count and PFS and/or OS.

Secondary endpoints were the correlation between specific BM lymphocyte population patterns and PFS and/ or OS, and the correlation between BM relative lymphocyte subtype count and CR (MRD negative or positive).

Statistical methods. Data were described by absolute and relative frequencies of categorical variables and median (minimum-maximum) of quantitative variables. For 
comparison of the categorical variables in groups, Fisher's exact test was used; in the case of quantitative variables, the Mann-Whitney U test was adopted. OS, PFS, TTP, and duration of response (DOR) were plotted using KaplanMeier methodology. The log-rank test was used to estimate the statistical significance of the difference between the curves. Association of risk factors with time-dependent endpoints was assessed using univariate Cox proportional hazards model. Hierarchical clustering based on Ward's algorithm was performed to defined homogenous groups of patients based on cell populations; variables were centered before entering the multivariate analysis. A p-value $<0.05$ was considered statistically significant (all tests two-sided). The analysis was performed in the SPSS software (IBM Corp. Released 2017. IBM SPSS Statistics for Windows, Version 25.0. Armonk, NY: IBM Corp.) and software R version 3.4.2 (www.r-projec.org).

\section{Results}

Patients and treatment results. PI-based induction treatment was administered in 60.2\% (59/98) of patients, PI + IMID treatment in 30.6\% (30/98) of patients, and IMIDbased treatment in $9.2 \%(9 / 98)$ of patients. The median number of induction treatment cycles was 4 (range 2-12). The characteristics of patients' demographic and treatment data are summarized in Table 1.

CR was achieved in $35.7 \%$ (35/98) of patients, very good partial response (VGPR) or better was achieved in $66.3 \%$ $(65 / 98)$, and partial response (PR) or better in $86.7 \%(85 / 98)$.

MRD status by MFC, as previously described, was assessed in $60.0 \%(21 / 35)$ of patients achieving CR. MRD negative CR was confirmed in $13.3 \%$ (13/98) of all patients.

The median PFS was 30.1 months [95\% CI (25.6-34.5)], median TTP 32.5 months [95\% CI (19.5-45.5)], median DOR 34.3 months [95\% CI (16.0-52.6)], and median OS 91.7 months [95\% CI (NA-NA)]. Median follow-up was 34.4 months [95\% (CI 4.4-107.6)].

All treatment results are summarized in Table 2 and Figure 1.

BM lymphocyte subpopulation-association with PFS or OS. Association of lymphocyte subpopulations with PFS and OS is shown in Table 3. An increase of memory B-cells proportion was significantly associated with inferior median PFS [HR 1.089 (95\% CI: 1.023-1.160), p=0.008] and median OS [HR 1.170 (95\% CI: 1.074-1.274), p<0.001]. Flow cytometry dot-plots of B lymphocyte subpopulations are presented in Figure 2. An increase of CD $56^{+} \mathrm{NK} / \mathrm{NKT}$ cells proportion was significantly associated with inferior median OS [HR 1.057 (95\% CI: 1.009-1.108), $\mathrm{p}=0.020]$, but not with median PFS.

BM lymphocyte subpopulation-multivariate association with PFS or OS. Based on Ward's method, three groups of patients with a characteristic lymphocyte subpopulations pattern in the BM were found: the first group (group 1) with $\mathrm{T}$ cells and mature B cells predominant pattern, the second
Table 1. Baseline characteristics (all patients; $\mathbf{n}=98$ ).

\begin{tabular}{|c|c|c|}
\hline \multicolumn{2}{|c|}{ Baseline characteristics at 1 st line initiation } & \multirow{2}{*}{$\begin{array}{l}\text { Statistics }^{*} \\
49(50.0 \%)\end{array}$} \\
\hline Female sex & & \\
\hline Age & Median (min-max) & $59(38-66)$ \\
\hline Follow-up (months) & Median (min-max) & $34.4(4.4-107.6)$ \\
\hline \multirow[t]{5}{*}{ M-protein type } & $\operatorname{IgG}$ & $56(57.1 \%)$ \\
\hline & IgA & $22(22.4 \%)$ \\
\hline & LC only & $18(18.4 \%)$ \\
\hline & $\operatorname{IgD}$ & $1(1.0 \%)$ \\
\hline & Nonsecretory & $1(1.0 \%)$ \\
\hline \multirow[t]{2}{*}{ Light chain type $(\mathrm{n}=97)^{\dagger}$} & Kappa & $60(61.9 \%)$ \\
\hline & Lambda & $37(38.1 \%)$ \\
\hline \multirow[t]{3}{*}{ ISS $(n=96)$} & Stage 1 & $43(44.8 \%)$ \\
\hline & Stage 2 & $33(34.4 \%)$ \\
\hline & Stage 3 & $20(20.8 \%)$ \\
\hline \multirow[t]{3}{*}{ ECOG PS $(n=94)$} & $0-1$ & $70(74.5 \%)$ \\
\hline & 2 & $19(20.2 \%)$ \\
\hline & $3-4$ & $5(5.3 \%)$ \\
\hline Extramedullary mass & & $13(13.4 \%)$ \\
\hline \multirow[t]{3}{*}{ Cytogenetic risk ${ }^{*}$} & Standard risk & $27(27.6 \%)$ \\
\hline & High risk & $14(14.3 \%)$ \\
\hline & Not available & $57(58.2 \%)$ \\
\hline \multirow[t]{3}{*}{ Induction regimen } & PI-based & $59(60.2 \%)$ \\
\hline & PI+IMID-based & $30(30.6 \%)$ \\
\hline & IMID-based & $9(9.2 \%)$ \\
\hline Number of induction cycles & Median (min-max) & $4(2-12)$ \\
\hline
\end{tabular}

Notes: ${ }^{\star} \mathrm{n}(\%)$ in case of categorical variables, median (minimum-maximum) in case of continuous variables; ${ }^{\dagger}$ not assessed in nonsecretory MM; ${ }^{*}$ high risk defined as presence of $\mathrm{t}(4 ; 14), \mathrm{t}(14 ; 16)$ or del $(17 \mathrm{p} 13)$; samples collected at time of MM diagnosis. Abbreviations: Ig-immunoglobulin; LC-light chains; M-protein-monoclonal protein; ISS-international staging system; ECOG PS-performance status developed by Eastern Cooperative Oncology Group; IMID-immunomodulatory drugs; PI-proteasome inhibitors; ASCT-autologous stem cell transplant.

Table 2. Final response to induction therapy and MRD status (all pa-

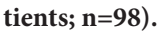

\begin{tabular}{ll}
\hline Final response and MRD status & $\mathbf{n}(\%)$ \\
\hline Final response to induction therapy & \\
CR & $35(35.7 \%)$ \\
CR+MRD negative & $13(13.3 \%)$ \\
CR+MRD positive & $8(8.2 \%)$ \\
CR+MRD not assessed & $14(14.3 \%)$ \\
VGPR & $30(30.6 \%)$ \\
PR & $20(20.4 \%)$ \\
MR & $4(4.1 \%)$ \\
SD & $3(3.1 \%)$ \\
PD & $6(6.1 \%)$ \\
ORR $(P R+)$ & $85(86.7 \%)$ \\
\hline
\end{tabular}

Note: ${ }^{\star}$ assessed 90-100 days after induction therapy. Abbreviations: MRDminimal residual disease; CR-complete response; VGPR-very good partial response; PR-partial response; $\mathrm{MR}$-minimal response; $\mathrm{SD}$-stable disease; $\mathrm{PD}$-progressive disease; ORR-overall response rate.

group (group 2) with a similar distribution of T and B cells, and the third group (group 3 ) with $\mathrm{T}$ cells and immature $\mathrm{B}$ cells predominant pattern. 

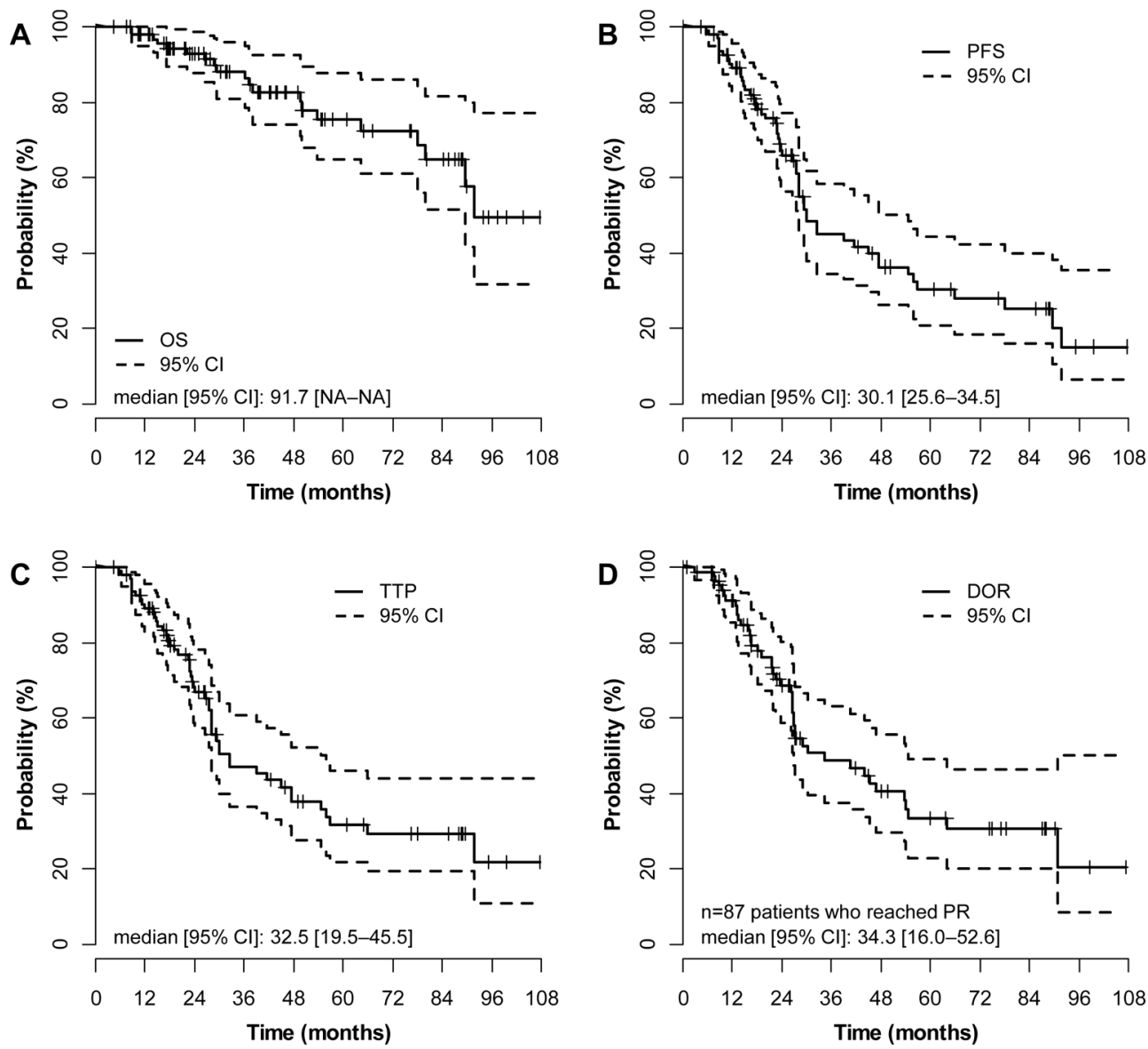

Figure 1. A) Overall survival (OS) from treatment initiation, B) (PFS), C) time to progression (TTP), and D) duration of response (DOR).

All three groups were comparable in treatment response achievement, PFS and OS intervals, and MRD status. All results including lymphocyte subtypes distribution in different patterns are summarized in Table 4 and Figure 3.

BM lymphocyte subpopulation - association with MRD negative $\mathrm{CR}$ and treatment response. MRD was assessed in $60.0 \%(21 / 35)$ of patients achieving CR. There was no significant difference in lymphocytes subpopulation according to MRD status. We found a higher proportion of memory B cells subpopulation in non-responding patients (minimal response and worse) when compared to patients achieving CR [3.8\% (range $0.5-35.0$ ) vs. $1.0 \%$ (range 0.1-12.5); $\mathrm{p}=0.001]$. Moreover, in non-responding patients, memory $\mathrm{T}$ cells subpopulation was elevated when compared to patients achieving CR [33.4\% (range $21.0-56.2$ ) vs. $25.0 \%$ (range 9.6-52.9); $\mathrm{p}=0.022$. Results are summarized in Table 5.

Figure 2. Flow cytometry analysis of B cell subpopulations in BM. A) total B lymphocytes (dark blue); B) memory B cells (pink) from total B cells; C-E) subpopulations of B lymphocytes-preB I (green), preB II (yellow), immature (light blue), mature (purple).
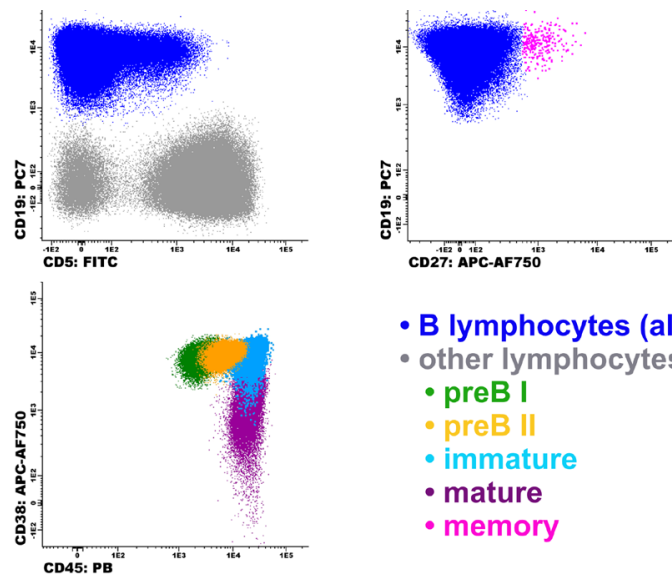

- B lymphocytes (all)

- other lymphocytes

- preB I

- preB \|I

- immature

- mature

- memory
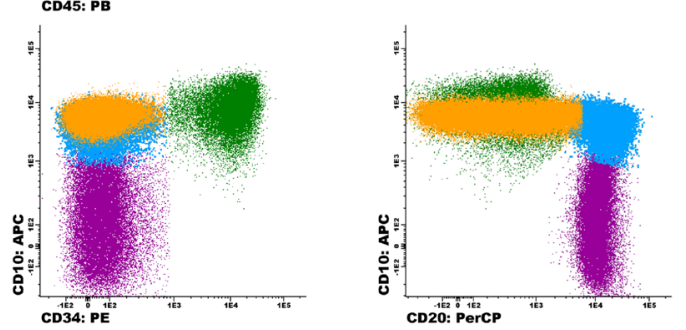
Table 3. Association of representation of respective cell population in bone marrow with OS and PFS from treatment initiation.

\begin{tabular}{llc}
\hline Cell population in bone marrow & Hazard ratio (95\% CI) & p-value \\
\hline Overall survival & & \\
B cells (\%) & $0.987(0.963-1.011)$ & 0.287 \\
Pre B I cells (\%) & $0.947(0.829-1.082)$ & 0.422 \\
Pre B II cells (\%) & $0.986(0.960-1.012)$ & 0.294 \\
Immature B cells (\%) & $0.963(0.881-1.053)$ & 0.407 \\
Mature B cells (\%) & $1.015(0.993-1.038)$ & 0.179 \\
Memory B cells (\%) & $1.170(1.074-1.274)$ & $<\mathbf{0 . 0 0 1}$ \\
T cells (\%) & $1.004(0.982-1.027)$ & 0.710 \\
Memory T cells (\%) & $1.029(0.983-1.078)$ & 0.223 \\
Activated memory T cells (\%) & $0.987(0.938-1.038)$ & 0.605 \\
NK cells (\%) & $1.031(0.987-1.078)$ & 0.167 \\
NK/NKT cells (\%) & $1.057(1.009-1.108)$ & $\mathbf{0 . 0 2 0}$ \\
NK subset (\%) & $1.000(0.975-1.026)$ & 0.998 \\
Progression-free survival & & \\
B cells (\%) & $0.991(0.977-1.005)$ & 0.213 \\
Pre B I cells (\%) & $0.967(0.903-1.035)$ & 0.331 \\
Pre B II cells (\%) & $0.998(0.984-1.013)$ & 0.822 \\
Immature B cells (\%) & $1.030(0.996-1.066)$ & 0.087 \\
Mature B cells (\%) & $0.999(0.986-1.013)$ & 0.907 \\
Memory B cells (\%) & $1.089(1.023-1.160)$ & $\mathbf{0 . 0 0 8}$ \\
T cells (\%) & $1.009(0.995-1.023)$ & 0.228 \\
Memory T cells (\%) & $1.029(0.998-1.061)$ & 0.069 \\
Activated memory T cells (\%) & $0.992(0.966-1.018)$ & 0.546 \\
NK cells (\%) & $0.996(0.966-1.028)$ & 0.815 \\
NK/NKT cells (\%) & $0.985(0.945-1.025)$ & 0.451 \\
NK subset (\%) & $0.999(0.985-1.013)$ & 0.872 \\
\hline
\end{tabular}

\section{Discussion}

Multiple myeloma pathogenesis is a complex and not fully understood process including dysregulation of the host's immune surveillance. A key mechanism of antitumor immune surveillance is the recognition of tumor cells by T and NK cells and their subsequent cytotoxic lysis [12]. There are a few regulatory mechanisms of the immune response. FoxP3 positive Treg cells effectively modulate the immune response $[12,23]$. In the case of MM, their role is unclear and the results describing their prognostic significance differ [23]. In new insights, even B cells have an important regulatory function in immune surveillance [24].

Processes in the immune system can be described in a simplified manner by proportional changes in immune cells' representation evaluated by flow cytometry. Several papers have been published focusing on how the representation of immune cells in vivo correlates with the prognosis of MM patients. Immunophenotyping studies have been performed in patients at specific endpoints of MM disease course (i.e., at the time of diagnosis, pre-ASCT, post-ASCT, relapse, in long-term response, etc.) [16-19].

This paper describes the prognostic significance of the BM lymphocyte subsets representation in MM patients after ASCT. In this study, an unselected group of MM patients treated with standard-of-care induction regimens were enrolled $[25,26]$. BM sampling was not affected by ongoing consolidation or maintenance treatment.

Table 4. Comparison of groups of patients (defined in cluster analysis) in representation of cell populations, response to treatment, and MRD status.

\begin{tabular}{|c|c|c|c|c|}
\hline Cell populations* & Group $1(n=20)$ & Group $2(n=31)$ & Group $3(n=30)$ & p-value ${ }^{\dagger}$ \\
\hline B cells $(\%)$ & $16.1(0.9-38.2)$ & $45.1(21.9-73.1)$ & $13.7(1.1-44.0)$ & $<0.001$ \\
\hline Pre B I cells $(\%)^{+}$ & $2.0(0.0-7.0)$ & $8.9(1.6-19.8)$ & $7.6(0.4-17.1)$ & $<0.001$ \\
\hline Pre B II cells $(\%)^{+}$ & $14.4(0.0-47.7)$ & $58.8(32.8-73.6)$ & $51.5(33.7-75.2)$ & $<0.001$ \\
\hline Immature B cells $(\%)^{+}$ & $15.8(0.0-72.1)$ & $12.6(4.7-23.7)$ & $12.8(1.2-30.9)$ & 0.481 \\
\hline Mature B cells $(\%)^{+}$ & $60.0(23.2-100.0)$ & $18.6(6.1-42.5)$ & $25.3(4.3-48.3)$ & $<0.001$ \\
\hline Memory B cells $(\%)^{+}$ & $2.8(0.3-35.0)$ & $0.7(0.1-4.0)$ & $1.0(0.1-7.7)$ & 0.001 \\
\hline $\mathrm{T}$ cells $(\%)$ & $61.9(29.2-85.0)$ & $44.8(17.1-64.3)$ & $72.9(43.4-88.8)$ & $<0.001$ \\
\hline Memory T cells $(\%)^{+}$ & $28.2(13.3-56.2)$ & $26.0(8.0-50.6)$ & $28.4(9.6-54.2)$ & 0.673 \\
\hline Activated memory T cells $(\%)^{+}$ & $19.0(5.6-37.9)$ & $30.6(5.3-56.1)$ & $25.2(6.4-49.2)$ & 0.003 \\
\hline NK cells $(\%)$ & $19.4(6.2-59.6)$ & $11.2(3.3-27.8)$ & $12.0(0.5-31.6)$ & 0.001 \\
\hline NK/NKT cells $(\%)^{+}$ & $12.6(7.7-51.1)$ & $9.0(3.0-29.9)$ & $10.0(1.5-37.6)$ & 0.048 \\
\hline NK subset $(\%)^{+}$ & $85.3(23.2-97.3)$ & $85.0(60.8-95.3)$ & $55.6(32.3-87.2)$ & $<0.001$ \\
\hline Final response to treatment & & & & p-value ${ }^{\ddagger}$ \\
\hline $\mathrm{CR}$ & $7(35.0 \%)$ & $10(32.3 \%)$ & $13(43.3 \%)$ & \multirow{4}{*}{0.768} \\
\hline VGPR & $5(25.0 \%)$ & $9(29.0 \%)$ & $9(30.0 \%)$ & \\
\hline $\mathrm{PR}$ & $4(20.0 \%)$ & $9(29.0 \%)$ & $4(13.3 \%)$ & \\
\hline MR-PD & $4(20.0 \%)$ & $3(9.7 \%)$ & $4(13.3 \%)$ & \\
\hline \multicolumn{5}{|l|}{ MRD status in $\mathrm{CR}^{*}$} \\
\hline MRD negative CR & $0(0.0 \%)$ & $5(62.5 \%)$ & $8(80.0 \%)$ & \multirow{2}{*}{0.055} \\
\hline MRD positive $C R$ & $3(100.0 \%)$ & $3(37.5 \%)$ & $2(20.0 \%)$ & \\
\hline
\end{tabular}

Notes: ${ }^{*} \mathrm{n}(\%)$ in case of categorical variables, median (minimum-maximum) in case of continuous variables; ${ }^{\dagger}$ statistical significance determined using Kruskal-Wallis test, p-values bellow significance level in bold; *statistical significance determined using Fisher's exact test in case of categorical variables and Mann-Whitney U test in case of continuous variables, p-values bellow significance level in bold; ${ }^{+}$percentage from all B-cells (T-cells, NK-cells respectively) 

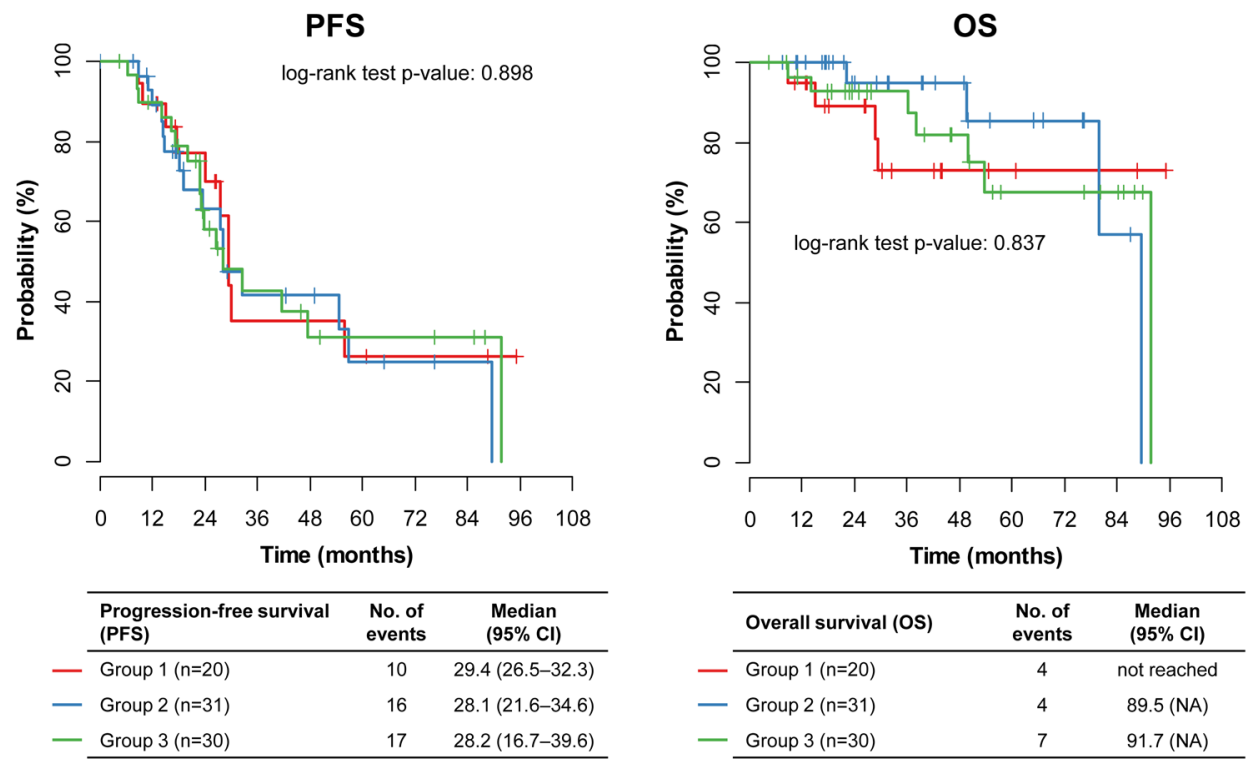

Figure 3. Progression-free survival (PFS) and overall survival (OS) in groups of patients defined in cluster analysis.

Table 5. Proportion of respective cell population in bone marrow according to MRD status and treatment response.

\begin{tabular}{|c|c|c|c|c|c|c|}
\hline \multirow{2}{*}{ Cell populations } & \multicolumn{3}{|c|}{ CR with MRD status ${ }^{*}$} & \multicolumn{3}{|c|}{ Non-responsive patients ${ }^{*}$} \\
\hline & Negative $(n=13)$ & Positive $(n=8)$ & p-value & $\mathrm{CR}(\mathrm{n}=35)$ & $M R+S D+P D(n=13)$ & p-value \\
\hline B cells $(\%)$ & $33.2(8.4-73.1)$ & $29.6(5.9-54.4)$ & 0.717 & $26.9(0.9-73.1)$ & $17.6(1.3-50.6)$ & 0.125 \\
\hline PreB I cells $(\%)^{\dagger}$ & $9.1(3.2-15.6)$ & $6.1(0.0-10.0)$ & 0.051 & $7.7(0.0-15.6)$ & $5.3(0.0-14.0)$ & 0.424 \\
\hline PreB II cells $(\%)^{\dagger}$ & $56.2(40.1-73.6)$ & $51.0(0.0-74.9)$ & 0.277 & $51.9(0.0-74.9)$ & $46.4(0.0-75.2)$ & 0.579 \\
\hline Immature B cells $(\%)^{\dagger}$ & $13.1(10.8-20.4)$ & $14.0(0.0-21.0)$ & 0.856 & $13.8(0.0-42.1)$ & $12.5(0.0-72.1)$ & 0.223 \\
\hline Mature B cells $(\%)^{\dagger}$ & $19.6(4.3-43.6)$ & $25.7(6.4-100.0)$ & 0.128 & $24.9(4.3-100.0)$ & $26.4(7.5-99.3)$ & 0.675 \\
\hline Memory B cells (\%) ${ }^{\dagger}$ & $0.7(0.1-4.0)$ & $1.1(0.4-4.9)$ & 0.384 & $1.0(0.1-12.5)$ & $3.8(0.5-35.0)$ & 0.001 \\
\hline T cells $(\%)$ & $53.2(17.1-82.1)$ & $53.7(29.2-80.6)$ & 0.913 & $56.2(16.3-82.1)$ & $72.4(31.9-79.9)$ & 0.084 \\
\hline Memory T cells $(\%)^{\dagger}$ & $24.6(9.6-39.4)$ & $26.8(13.5-41.4)$ & 0.426 & $25.0(9.6-52.9)$ & $33.4(21.0-56.2)$ & 0.022 \\
\hline Activated memory T cells (\%) ${ }^{\dagger}$ & $23.6(5.3-41.0)$ & $19.7(5.6-38.1)$ & 0.469 & $20.6(5.3-44.3)$ & $28.3(9.8-39.1)$ & 0.171 \\
\hline NK cells $(\%)$ & $12.2(0.5-31.6)$ & $12.2(4.3-59.6)$ & 0.772 & $13.3(0.5-59.6)$ & $16.3(3.3-20.3)$ & 0.539 \\
\hline NK/NKT cells $(\%)^{\dagger}$ & $7.5(5.0-37.6)$ & $13.8(5.7-51.1)$ & 0.168 & $9.0(4.5-51.1)$ & $12.5(1.5-18.2)$ & 0.977 \\
\hline NK subset $(\%)^{\dagger}$ & $70.3(32.3-95.2)$ & $71.6(34.4-97.3)$ & 0.800 & $72.9(32.3-97.3)$ & $79.0(23.2-94.7)$ & 0.345 \\
\hline
\end{tabular}

Notes: "described using median (minimum-maximum), statistical significance determined using two-tailed Mann-Whitney U test, p-values bellow significance level in bold, $\mathrm{n}=$ patients with defined response; ${ }^{\dagger}$ cells percentage from all B-cells (T-cells, NK-cells respectively); ${ }^{*}$ patients with final response CR and MRD status not available excluded

We found a significant correlation of a higher proportion of memory B cells with unfavorable prognosis. This finding is surprising when in the analysis published by Paiva et al., a higher proportion of memory B cells was associated with a better prognosis [19]. Differences between our and previously mentioned analysis could be explained by differences in the timing of BM sampling. In Paiva's analysis, patients were sampled at the time of maintenance treatment with IMIDs, but in our group of patients, there was a treatment-free interval of at least 3 months before BM sampling. Moreover, we did not prove any other B cells subgroup as a risk factor for treatment response, while in the previously mentioned analysis, naïve $\mathrm{B}$ cells were also connected with a favorable prognosis [19].
Another explanation of our results may be that in MM, memory B cells subset may serve as a source of clonotypic $B$ cells with the potential to transform into MM cells [27]. In work published by Rasmussen et al., differences between clonotypic memory B cells and normal memory B cells were found in the expression of chemokine receptors (CXCR5, CCR7). While normal memory B cells were recirculating between $\mathrm{PB}, \mathrm{BM}$, and lymphatic organs, clonotypic memory $\mathrm{B}$ cells had the higher homing potential to $\mathrm{BM}$ and lymphatic tissue [28]. That may explain the different prognostic significance of memory B cells (probably normal) in PB in Paiva's work and BM memory B cells (probably clonotypic) in our analysis [19]. 
Other papers showed that total B cell level in MM patients after ASCT had no effect on the patient's prognosis what is in concordance with our findings [17, 18].

In our analysis, we found no association of $\mathrm{T}$ cells with post-transplant prognosis. These results are consistent with previously published results of PB T cells [16-18].

In a deeper analysis of post-ASCT peripheral $\mathrm{T}$ cells sub-populations, a higher proportion of $\gamma \delta \mathrm{T}$ cells correlated with longer PFS and OS, especially in patients without maintenance treatment. However, in the case of $\gamma \delta \mathrm{T}$ cells, results could be influenced by administrated bisphosphonates [29]. A higher proportion of $\mathrm{CD} 4^{+}$central memory $\mathrm{T}$ cells correlated with a longer OS but not PFS in post-transplant MM patients [17]. We found a higher proportion of memory $\mathrm{T}$ cells in non-responsive patients but not as a risk factor for PFS or OS length. Moreover, there was no significant change of memory $\mathrm{T}$ cell proportion in specific lymphocyte patterns, found in our analysis. Other important $\mathrm{T}$ cell subpopulations, such as effector memory T, Tregs, Th17, etc., were not analyzed in this study. Our BM samples were limited by volume and evaluated primarily for clonality assessment.

NK cells are one of the major anti-tumor immunity components in other malignancies, such as Hodgkin lymphoma or melanoma [12, 13, 30, 31]. However, changes in their representation in BM did not correlate with better prognosis in MM patients after ASCT. We found a higher proportion of $\mathrm{CD}^{5} 6^{+} \mathrm{NK} / \mathrm{NKT}$ cells associated with inferior OS. As the whole population of NK cells was not associated with inferior OS, it seems that only $\mathrm{CD}^{2} 6^{+}$NKT cells are responsible for this association. However, a higher proportion of these cells was not associated with inferior PFS or with a non-responsive group of patients. In the literature, their representation in a single assessment had often limited value for the prognosis of MM patients [17, 19]. Early reconstitution of NK lymphocytes within 1 month after ASCT and/or their higher numbers in $\mathrm{PB}$ in long-term remission appears to correlate with longer PFS $[11,18]$.

BM lymphocyte reconstruction after ASCT depends on the diagnosis and previous therapy. In a paper analyzing various hematopoietic malignancies, normalization of $\mathrm{B}$ and $\mathrm{T}$ cells levels was usually until day 20 after ASCT [32]. Another analysis of MM patients showed the beginning of B cells recovery 6 months after ASCT. Full B-cell recovery happened within one year [18]. In concordance to the previously mentioned work, normalization of polyclonal immunoglobulin levels happened within one year [33]. The process of $\mathrm{T}$ and NK cells' recovery in MM patients after ASCT varies. While $\mathrm{CD}^{+} \mathrm{T}$ cells and NK cell levels were comparable with healthy donors within one month, $\mathrm{CD} 4^{+} \mathrm{T}$ cells merely reached normal levels [18].

From so far published analysis in MM patients, reconstruction of immune surveillance is a complex process, strongly affected by concomitant maintenance treatment. Achieving and maintaining MRD negativity is currently considered to be the strongest and independent prognostic factor of the length of PFS and OS in MM patients [6-8]. Our analysis showed no specific changes in examined lymphocyte populations in MRD-negative patients. Similar results were also reported regardless of ASCT in elderly patients [19].

In conclusion, the representation of different lymphocyte subpopulations in routine BM assessment after ASCT has unclear prognostic significance in our hands. We found a higher proportion of memory B cells associated with the inferior prognosis. It remains to be seen if this subset contains clonotypic B cells with the potential to regenerate and maintain the population of MM cells.

Moreover, due to small differences in the representation of memory $\mathrm{B}$ cells populations in responsive and non-responsive patients, it may be difficult to use these cells as a prognostic marker in routine clinical practice. We found no specific lymphocyte sub-population or pattern associated with MRD negative CR. For the better prognostic impact of lymphocytes' subgroups analysis, more complex or continuous analyses should be done.

Acknowledgments: The authors would like to thank all patients, their caregivers, and RMG data coordinators for participating in this study. This work was supported by the grant of the Ministry of Health of the Czech Republic AZV 17-29343A.

\section{References}

[1] KUMAR SK, RAJKUMAR SV, DISPEZIERI A, LACY MQ, HAYMAN RS et al. Improved survival in multiple myeloma and the impact of novel therapies. Blood 2008; 111: 25162520. https://doi.org/10.1182/blood-2007-10-116129

[2] SAN-MIGUEL JF, MATEOS MV. Can multiple myeloma become a curable disease? Haematologica 2011; 96: 1246-1248. https://doi.org/10.3324/haematol.2011.051169

[3] MOREAU P, HULIN C, MACRO M, CAILLOT D, CHALETEIX C et al. VTD is superior to VCD prior to intensive therapy in multiple myeloma: Results of the prospective IFM2013-04 trial. Blood 2016; 127: 2569-2574. https://doi. org/10.1182/blood-2016-01-693580

[4] LANDGREN O, SONNEVELD P, JAKUBOWIAK A, MOHTY M, ISKANDER KS et al. Carfilzomib with immunomodulatory drugs for the treatment of newly diagnosed multiple myeloma. Leukemia 2019; 33: 2127-2143. https:// doi.org/10.1038/s41375-019-0517-6

[5] GAY F, LAROCCA A, WIJERMANS P, CAVALLO F, ROSSI D et al. Complete response correlates with longterm progression-free and overall survival in elderly myeloma treated with novel agents: analysis of 1175 patients. Blood 2011; 117: 3025-3031. https://doi.org/10.1182/ blood-2010-09-307645

[6] PAIVA B, VIDRIALES MB, CERVERO J, MATEO G, PEREZ JJ et al. Multiparameter Flowcytometric remission is the most relevant prognostic factor for multiple myeloma patients who undergo autologous stem cell transplantation. Blood 2008; 112: 4017-4023. https://doi.org/10.1182/ blood-2008-05-159624 
[7] CHAKRABORTY R, MUCHTAR E, KUMAR SK, JEVREMOVIC D, BUADI FK et al. Impact of Post-Transplant Response and Minimal Residual Disease on Survival in Myeloma with High-Risk Cytogenetics. Biol Blood Marrow Transplant 2017; 23: 598-605. https://doi.org/10.1016/j. bbmt.2017.01.076

[8] LANDGREN O, DEVLIN S, BOULAD M, MAILANKODY $S$. Role of MRD status in relation to clinical outcomes in newly diagnosed multiple myeloma patients: a meta-analysis. Bone Marrow Transplant 2016; 51: 1565-1568. https:// doi.org/10.1038/bmt.2016.222

[9] SAN-MIGUEL JF, PAIVA B. How deep is the myeloma iceberg? Blood 2018; 132: 2424-2425. https://doi.org/10.1182/ blood-2018-10-878637

[10] MARTINEZ-LOPEZ J, BLADE J, MATEOS MV, GRANDE C, ALEGRE A et al. Long-term prognostic significance of response in multiple myeloma after stem cell transplantation. Blood 2011; 118: 529-534. https://doi.org/10.1182/ blood-2011-01-332320

[11] PESSOA DE MAGALHAES RJ, VIDRIALES MB, PAIVA B, FERNANDEZ-GIMENEZ C, GARCIA-SANZ R et al. Analysis of the immune system of multiple myeloma patients achieving long-term disease control by multidimensional flow cytometry. Haematologica 2013; 98: 79-86. https://doi. org/10.3324/haematol.2012.067272

[12] GUILLEREY C, NAKAMURA K, VUCKOVIC S, HILL GR, SMYTH MJ. Immune responses in multiple myeloma: role of the natural immune surveillance and potential of immunotherapies. Cell Mol Life Sci 2016; 73: 1569-1589. https://doi. org/10.1007/s00018-016-2135-Z

[13] PONZETTAA, BENIGNIG, ANTONANGELIF, SCIUMEG, SANSEVIERO E et al. Multiple myeloma impairs bone marrow localization of effector natural killer cells by altering the chemokine microenvironment. Cancer Res 2015; 75: 47664777. https://doi.org/10.1158/0008-5472.CAN-15-1320

[14] GUILLEREY C, FARRARI DE ANDRADE L, VUCKOVIC S, MILES K, NGIOW SF et al. Immunosurveillance and therapy of multiple myeloma are CD226 dependent. J Clin Invest 2015; 125: 2077-2089. https://doi.org/10.1172/JCI77181

[15] MCEWEN-SMITH RM, SALIO M, CERUNDOLO V. The regulatory role of invariant $\mathrm{NKT}$ cells in tumor immunity. Cancer Immunol Res 2015; 3: 425-435. https://doi. org/10.1158/2326-6066.CIR-15-0062

[16] KAY NE, LEONG TL, BONE N, VESOLE DH, GREIPP PR et al. Blood levels of immune cells predict survival in myeloma patients: results of an Eastern Cooperative Oncology Group phase 3 trial for newly diagnosed multiple myeloma patients. Blood 2001; 98: 23-28. https://doi.org/10.1182/ blood.v98.1.23

[17] HO CM, MCCARTHY PL, WALLACE PK, ZHANG Y, FORA A et al. Immune signatures associated with improved progression-free and overall survival for myeloma patients treated with AHSCT. Blood Adv 2017; 1: 1056-1066. https:// doi.org/10.1182/bloodadvances.2017005447

[18] RUEFF J, MEDINGER M, HEIM D, PASSWEG J, STERN M. Lymphocyte subset recovery and outcome after autologous hematopoietic stem cell transplantation for plasma cell myeloma. Biol Blood Marrow Transplant 2014; 20: 896-899. https://doi.org/10.1016/j.bbmt.2014.03.007
[19] PAIVA B, CEDENA MT, PUIG N, ARANA P, VIDRIALE $\mathrm{MB}$ et al. Minimal residual disease monitoring and immune profiling in multiple myeloma in elderly patients. Blood 2016; 127: 3165-3174. https://doi.org/10.1182/ blood-2016-03-705319

[20] PASIARSKI M, GRYWALSKA E, KOSMACZEWSKA A, GOZDZ S, STECKIEWICZ P et al. Assessment of peripheral blood and bone marrow T, NK, NKT and dendritic cells in patients with multiple myeloma. Postepy Hig Med Dosw (Online) 2015; 69: 1435-1442.

[21] SAN-MIGUEL JF, GONZALEZ M, GASCON A, MORO MJ, HERNANDEZ JM, et al. Cooperative Group for the Study of Monoclonal Gammopathies. Lymphoid subsets and prognostic factors in multiple myeloma. Br J Haematol 1992; 80: 305-309. https://doi.org/10.1111/j.1365-2141.1992. tb08137.x

[22] RAJKUMAR SV, DIMOPOULOS MA, PALUMBO A, BLADE J, MERLINI G et al. International Myeloma Working Group updated criteria for the diagnosis of multiple myeloma. Lancet Oncol 2014; 15: e538-548. https://doi. org/10.1016/S1470-2045(14)70442-5

[23] LAD D, HUANG Q, HOEPPLI R, GARCIA R, XU L et al. Evaluating the role of Tregs in the progression of multiple myeloma. Leuk Lymphoma 2019; 60: 2134-2142. https://doi. org/10.1080/10428194.2019.1579324

[24] SARVAIA A, MADRIGAL J, SAUDEMONT A. B cell regulation in cancer and anti-tumor immunity. Cell Mol Immunol 2017; 14: 662-674. https://doi.org/10.1038/cmi.2017.35

[25] CORIU D, DYTFELD D, NIEPEL D, SPICKA I, MARKULJAK I et al. Real world multiple myeloma management practice patterns and outcomes in selected Central and Eastern European countries. Pol Arch Intern Med 2018; 128: 500511. https://doi.org/10.20452/pamw.4305

[26] RAAB MS, CAVO M, DELFORGE M, DRIESSEN C, FINK L et al. Multiple myeloma: practice patterns across Europe. Br J Haematol 2016; 175: 66-76. https://doi.org/10.1111/ bjh.14193

[27] JOHNSEN HE, BØGSTED M, SCHMITZ A, STØVE BØDKER J, EL-GALALY TC et al. The myeloma stem cell concept, revisited: from phenomenology to operational terms. Haematologica 2016; 101: 1451-1459. https://doi.org/10.3324/ haematol.2015.138826

[28] RASMUSSEN T, LODAHL M, HANCKE S, JOHNSEN HE. In Multiple Myeloma Clonotypic CD38-/CD19+/CD27+ Memory B Cells Recirculate Through Bone Marrow, Peripheral Blood and Lymph Nodes. Leuk Lymphoma 2004; 45: 1413-1417. https://doi.org/10.1080/10428190410001655157

[29] KUNZMANN V, BAUER E, FEURLE J, WEISSINGER F, TONY HP et al. Stimulation of gammadelta T cells by aminobisphosphonates and induction of antiplasma cell activity in multiple myeloma. Blood 2000; 96: 384-392.

[30] VIVIER E, RAULET DH, MORETTA A, CALIGUIRI MA, ZITVOGEL L et al. Innate or adaptive immunity? The example of natural killer cells. Science 2011; 331: 44-49. https:// doi.org/10.1126/science.1198687

[31] PIETRA G, VITALE M, MORETTA L, MINGARI MC. How melanoma cells inactivate NK cells. Oncoimmunology 2012; 1: 974-975. https://doi.org/10.4161/onci.20405 
[32] KOEHNE G, ZELLER W, STOCKSCHLAEDR M, ZANDER AR. Phenotype of lymphocyte subsets after autologous peripheral blood stem cell transplantation. Bone Marrow Transplant 1997; 19: 149-156. https://doi.org/10.1038/ sj.bmt. 1700624
[33] GONZÁLEZ-CALLE V, CERDÁ S, LABRADOR J, SOBEJANO E, GONZÁLEZ-MENA B et al. Recovery of polyclonal immunoglobulins one year after autologous stem cell transplantation as a long-term predictor marker of progression and survival in multiple myeloma. Haematologica 2017; 102: 922-931. https://doi.org/10.3324/haematol.2016.158345 